\title{
Occlusion therapy in amblyopia with eccentric fixation
}

\section{Comparison of conventional, non-conventional (inverse), and red-filter occlusion}

\author{
S. R. K. MALIK, A. K. GUPTA, AND V. K. GROVER
}

Department of Ophthalmology, Maulana Azad Medical College and Associated Hospitals, New Delhi, India

Occlusion of the sound eye (conventional occlusion) introduced by Buffon (1 743) was the only treatment for amblyopia until Bangerter (1953) introduced occlusion of the amblyopic eye (non-conventional or inverse occlusion) combined with pleoptic treatment in cases of amblyopia with eccentric fixation. Mackensen, Kröner, and Postić (1965), von Noorden (1965), Postić (1966), Borgmann and Dielefeld (1967), and Ver Lee and Iacobucci (1967) found conventional occlusion of the sound eye to be as good as pleoptic treatment. On the other hand, Arruga (1962) and Cibis and Windsor (1967) favoured non-conventional (inverse) occlusion of the amblyopic eye. Brinker and Katz (1963) introduced red-filter occlusion to avoid the shortcomings of pleoptic treatment.

Because of the disparity in the results given by various authors, the present study was undertaken to provide comparative data and to ascertain the significance of such factors as age of patient, fixation pattern, refractive error, and strabismus in the response to occlusion therapy. This study includes a number of patients above the age of 12 yearsa group not discussed by other workers.

\section{Material and methods}

Seventy cases of amblyopia with eccentric fixation but no other ocular abnormality were selected for occlusion therapy. Pleoptics were not combined with any of the occlusion methods. The diagnosis of eccentric fixation was established and the degree of eccentric fixation determined by using the Linksz star graticule in Keeler's projectoscope. A distinction was made between eccentric fixation and eccentric viewing, and only cases with true eccentric fixation were included in this series. The eccentricity was graded according to the classification of Malik, Gupta, and Choudhry (1969). Visual acuity was measured by using Snellen's "Whole line optotypes".

The cases were divided into three groups:

Group I ( 8 cases) Conventional occlusion (of the unaffected eye)

Group II (24 cases) Non-conventional occlusion (of the affected eye)

Group III (28 cases) Red-filter occlusion (of the affected eye). 
Only one type of occlusion was used for each case. Each group was analysed by the following clinical features:

(a) Age of patient: 3 to 6, 7 to 9, 10 to 12, and above 12 years

(b) Type of eccentric fixation

(c) Degree of refractive error

(d) Type and degree of strabismus

Conventional and non-conventional occlusion was carried out by Doyne's occluder, taking care that no light entered the occluded eye; the occlusion was applied throughout the patient's waking hours.

Red-filter occlusion was carried out by the method described by Malik, Gupta, Choudhry, and Sen (1968a).

The patients were examined every fortnight to assess the improvement in visual acuity and fixation. The duration of treatment ranged from 6 to 30 weeks.

\section{Observations}

These are summarized in Tables I to IV.

The response to all types of occlusion was better in patients with less dense initial amblyopia and with eccentric fixation close to the fovea. With conventional occlusion 83.3 per cent. of cases showed improvement, and with non-conventional occlusion the results were relatively poor $(33 \cdot 3$ per cent.).

Table I Response of visual acuity to various methods of occlusion, by age group

\begin{tabular}{|c|c|c|c|c|c|c|}
\hline \multirow{2}{*}{$\begin{array}{l}\text { Age Group } \\
(y r s)\end{array}$} & \multicolumn{2}{|c|}{ Conventional } & \multicolumn{2}{|c|}{ Non-conventional } & \multicolumn{2}{|c|}{ Red-filter } \\
\hline & Same & Improved & Same & Improved & Same & Improved \\
\hline $3-6$ & $\mathbf{I}$ & 5 & 3 & - & 一 & 2 \\
\hline $7-9$ & $\mathbf{I}$ & $\underline{-}$ & 2 & - & $\mathbf{I}$ & 3 \\
\hline $10-12$ & - & 2 & 2 & I & 2 & I \\
\hline Above 12 & I & 8 & II & 5 & 10 & 9 \\
\hline Total & 3 & 15 & 18 & 6 & 13 & 15 \\
\hline
\end{tabular}

Table II Response of fixation to various methods of occlusion, by age group

\begin{tabular}{|c|c|c|c|c|c|c|}
\hline \multirow{2}{*}{$\begin{array}{l}\text { Age Group } \\
\text { (yrs) }\end{array}$} & \multicolumn{2}{|c|}{ Conventional } & \multicolumn{2}{|c|}{ Non-conventional } & \multicolumn{2}{|c|}{ Red-filter } \\
\hline & Same & Improved & Same & Improved & Same & Improved \\
\hline $3-6$ & 3 & 3 & 2 & $\mathbf{I}$ & $\mathbf{I}$ & $\mathbf{I}$ \\
\hline $7-9$ & $\mathbf{I}$ & - & $\mathbf{I}$ & $\mathbf{I}$ & $\mathbf{I}$ & 3 \\
\hline $10-12$ & - & 2 & 2 & I & I & 2 \\
\hline Above 12 & 4 & 5 & 13 & 3 & I I & 8 \\
\hline Total & 8 & 10 & 18 & 6 & 14 & 14 \\
\hline
\end{tabular}


Table III Overall improvement obtained by various methods of occlusion

\begin{tabular}{|c|c|c|c|c|}
\hline \multirow{3}{*}{ Type of occlusion } & \multirow{3}{*}{ Total cases } & \multicolumn{3}{|l|}{ Improvement } \\
\hline & & Visual acuity & Fixation & Total \\
\hline & & No. Per cent. & No. Per cent. & No. Per cent. \\
\hline $\begin{array}{l}\text { Conventional } \\
\text { Non-conventional } \\
\text { Red-filter }\end{array}$ & $\begin{array}{l}18 \\
24 \\
28\end{array}$ & $\begin{array}{r}1583 \cdot 3 \\
625 \cdot 0 \\
1553 \cdot 6\end{array}$ & $\begin{array}{rr}10 & 55 \cdot 5 \\
6 & 25 \cdot 0 \\
14 & 50 \cdot 0\end{array}$ & $\begin{array}{cc}15 & 83 \cdot 3 \\
8 & 33 \cdot 3 \\
16 & 57 \cdot 1\end{array}$ \\
\hline
\end{tabular}

Table IV Degree of refractive error related to overall improvement, by various methods of occlusion

\begin{tabular}{|c|c|c|c|c|c|c|c|c|}
\hline \multirow{3}{*}{$\begin{array}{l}\text { Type of } \\
\text { occlusion }\end{array}$} & \multicolumn{8}{|c|}{ Degree of refractive error (dioptres) } \\
\hline & \multicolumn{2}{|c|}{$0.50-2$} & \multicolumn{2}{|c|}{$2 \cdot 25-4$} & \multicolumn{2}{|c|}{$4 \cdot 25^{-6}$} & \multicolumn{2}{|c|}{ More than 6} \\
\hline & Same & Improved & Same & Improved & Same & Improved & Same & Improved \\
\hline $\begin{array}{l}\text { Conventional } \\
\text { Non-conventional } \\
\text { Red-filter }\end{array}$ & $\begin{array}{l}1 \\
4 \\
5\end{array}$ & $\begin{array}{l}4 \\
2 \\
7\end{array}$ & $\begin{array}{l}1 \\
5 \\
3\end{array}$ & $\begin{array}{l}7 \\
4 \\
6\end{array}$ & $\begin{array}{l}\text { I } \\
\text { I } \\
\text { I }\end{array}$ & $\begin{array}{l}2 \\
2 \\
1\end{array}$ & $\begin{array}{l}\overline{6} \\
3\end{array}$ & $\frac{2}{2}$ \\
\hline
\end{tabular}

\section{Discussion}

conventional ocglusion This gave the best results, especially with regard to improvement in visual acuity. The fixation pattern of the amblyopic eye and the density of the initial amblyopia were found to be more important than the age of the patient. Improvement was not related to the refractive error or to the presence or absence of strabismus.

Our results in cases of parafoveal fixation compare well with those of von Noorden ( 1965 ), who obtained improvement in $81 \cdot 8$ per cent. of patients with similar degrees of eccentric fixation, but von Noorden also had good results in cases with paramacular and peripheral fixation ( $9 \mathrm{I} \cdot 6$ and 90.6 per cent. respectively). We were unable to collect enough cases of this type of fixation suitable for conventional occlusion to make a strictly valid comparison, because most of our patients were older and needed to use the sound eye for their work. But our results agree with those of many other workers who have found that amblyopia with eccentric fixation can be improved by conventional occlusion: Scully (196r) 98.2 per cent.; Sternberg and Bohár (196r) 80 per cent.; Little and Ogilvie (1963) 75 per cent.; Mackensen and others (1965) 90 per cent.; von Noorden (1965) 93.4 per cent.; Catford (1967) 89.4 per cent. In almost all these reports the patients were under 12 years of age, but we found a good response to conventional occlusion in patients over 12 years old provided that the fixation was close to the fovea.

NON-CONVENTIONAL OGGLUSION Our results were poor as regards both fixation and visual acuity. This was true for all age groups and all types of fixation, although cases of erratic and parafoveal fixation showed better results than cases of peripheral fixation. The apparently better response of cases without manifest strabismus was due to the fact that these included more cases of erratic and parafoveal fixation. 
Our 33.6 per cent. improvement in this group may be compared with those of von Noorden (1965) 34.5 per cent., Andrée (1966) 25.0 per cent., and Malik and others (I968a) $30 \cdot 8$ per cent., but differs widely from those of Arruga (1962) $93 \cdot 0$ per cent. and Cibis and Windsor ( 1967$) 70 \cdot 0$ per cent. This discrepancy could be due to the fact that almost all Arruga's patients were under 4 years of age.

RED-FILTER OGCLUSION This gave encouraging results in both fixation and visual acuity. The response was better in patients under 12 years old $(77 \cdot 7$ per cent. improved) than in those over 12 years old $(47.4$ per cent. improved).

The results were good in cases of erratic and parafoveal fixation (Ioo and 62.5 per cent.) irrespective of the age of the patient.

We have previously reported better results in patients with small degrees of eccentric fixation (Malik, Sood, Gupta, and Choudhry, I968b) but only three of nine cases with paramacular fixation and one of four cases with more peripheral fixation (i.e. paracaecal and centrocaecal) showed improvement. This observation is contrary to the findings of most other workers who obtained excellent results even in cases of grossly eccentric fixation (Brinker and Katz, 1963; Binder, Engel, Ede, and Loon, I963; von Noorden, 1965; Cowle, Kunst, and Philpotts, 1967). This disparity may be explained by the assumption that the other workers were treating younger patients (under I I years) in whom the eccentric point is still in a stage of flux and more amenable to treatment. In our series, only one of two patients with paramacular fixation below 12 years of age showed improvement, and the one patient with peripheral fixation who improved was only 6 years old.

The response to red-filter occlusion was much better in cases with less than 4 dioptres of refractive error. This was related to the fixation pattern also; of eight patients with parafoveal fixation, five improved and the other three had a refractive error of more than 4 dioptres.

The presence or degree of strabismus had no prognostic effect on red-filter treatment (Table V).

Table V Strabismus related to overall improvement, by method of occlusion

\begin{tabular}{|c|c|c|c|c|c|c|}
\hline \multirow{2}{*}{ Strabismus } & \multicolumn{2}{|c|}{ Conventional } & \multicolumn{2}{|c|}{ Non-conventional } & \multicolumn{2}{|c|}{ Red-filter } \\
\hline & Same & Improved & Same & Improved & Same & Improved \\
\hline Absent & I & 3 & 4 & 3 & 2 & 5 \\
\hline $\begin{array}{r}\text { Unilateral Up to } 15^{\circ} \\
15-30^{\circ} \\
\end{array}$ & 2 & $\begin{array}{r}11 \\
1\end{array}$ & $\begin{array}{l}7 \\
4 \\
\end{array}$ & $\begin{array}{l}3 \\
2\end{array}$ & $\begin{array}{l}7 \\
3\end{array}$ & $\begin{array}{l}8 \\
2\end{array}$ \\
\hline $\begin{array}{r}\text { Alternating } \mathrm{Up}_{\mathrm{p}} \text { to } 15^{\circ} \\
\mathrm{I} 5 \text { to } 30^{\circ}\end{array}$ & $\overline{-}$ & - & $\bar{I}$ & - & - & $\underline{\mathbf{I}}$ \\
\hline Total & 3 & 15 & 16 & 8 & 12 & 16 \\
\hline
\end{tabular}

\section{Summary}

Seventy cases of amblyopia with eccentric fixation have been treated by conventional, non-conventional, and red-filter occlusion and the results have been assessed in relation to age of patient, fixation pattern, refractive error, and strabismus. Conventional and red-filter occlusion were better than non-conventional occlusion. The first improved both visual acuity and fixation and the second improved fixation. Patients with erratic 
and parafoveal fixation had a good prognosis regardless of their age. Refractive errors of more than 4 dioptres, even in younger patients with fixation close to the fovea, carry a poor prognosis with red-filter occlusion. The presence or absence of strabismus had little prognostic significance.

It is concluded that, wherever feasible, conventional occlusion should be tried first, especially in children. If it is not possible to get the co-operation of the patient for full-time occlusion of the sound eye because of dense amblyopia, red-filter occlusion may be used. Non-conventional occlusion is not of much therapeutic value unless it is combined with intensive pleoptic treatment.

\section{References}

ANDRÉe, G. (1966) v. Graefes Arch. Ophthal., r70, 257

ARRUGA, A. (1962) Trans. ophthal. Soc. U.K., 82, 45

BANGERTER, A. (1953) Ophthalmologica (Basel), 125, 398

BINDER, H. F., ENGEL, D., EDE, M. L., and Loon, L. (1963) Amer. orthopt. J., 13, 64

borgmann, h., and Dielefeld, м. (1967) Klin. Mbl. Augenheilk., r50, 325

BRINKer, W. R., and kATZ, s. L. (1963) Amer. J. Ophthal., 55, I033

BUFFON, G. L. L. COMTE DE (I 746) "Dissertation sur la cause du strabisme ou des yeux louches",

Mém. Acad. roy. Sci., Paris, 1743, p. 231

CATFORD, G. v. (1967) Trans. ophthal. Soc. U.K., 87, I 79

cIBIs, L., and windsor, c. (I967) Amer. orthopt. J., r7, 56

cowle, J. B., kUNST, J. H., and PhilpotTs, A. м. (I967) Brit. 7. Ophthal., 51, i65

uittle, J. G., and ogilvie, M. (1963) Trans. Canad. ophthal. Soc., 26, 240

mackensen, G., KRöner, B., and postić, G. (1965) Klin. Mbl. Augenheilk., 147, 2 I 3

MALIK, s. R. K., GUPTA, A. K., and GHOUDhry, s. (I969) Brit. J. Ophthal., 53, I88

$\longrightarrow,-\longrightarrow$, and SEN, D. K. (1968a) Ibid., 52, 839

- sood, G. C., GuPta, A. K., and choudhry, s. (1968b) Orient. Arch. Ophthal., 6, I 49

NOORDEN, G. K. von (1965) Arch. Ophthal. (Chicago), 73, 776

Postić, G. (I966) Bill. Soc. franc. Ophtal., 79, $35^{\circ}$

SCULly, J. (196I) Brit. med. J., 2, 16 ro

STERNBERG, A. R., and BOHÁR, A. (I96I) Ophthalmologica (Basel), r41, 229

VER LEE, D. L., and IACOBucci, I. (1967) Amer. J. Ophthal., 63, 244 